\title{
Research on Agricultural Products Cold Chain Logistics Safety Supervision System: Mechanism Improvement and Supervision Measures
}

\author{
Xin'gang Weng, Jiuyi An, Weifeng Chen \\ Beijing Wuzi University, Beijing, China \\ Email:anjiuyi@126.com
}

Received 2 December 2015; accepted 26 December 2015; published 29 December 2015

Copyright (C) 2015 by authors and Scientific Research Publishing Inc.

This work is licensed under the Creative Commons Attribution International License (CC BY). http://creativecommons.org/licenses/by/4.0/

\begin{abstract}
With the widespread concern in the community and increased government supervision, Chinese cold chain logistics quality and safety of agricultural products are being constantly improved, but quality safety management work of cold chain logistics of agricultural products started lately in China. There are many constraints, and the management is difficult, so the quality and safety supervision of agricultural products cold chain logistics is still inadequate. Based on the system analysis of agricultural products, the paper proposes mechanism improvement of cold chain logistics of agricultural products and analyzes measures of safety supervision system of cold chain logistics of agricultural products.
\end{abstract}

\section{Keywords}

Agricultural Products, Cold Chain Logistics, Mechanism Improvement, Safety Supervision System

\section{Introduction}

Law of Quality Safety of Agricultural Products adopted on April 29, 2006, established the system of supervision responsibilities of quality safety of agricultural products and ruled that management system of quality safety of agricultural products of exercise unified leadership, Department of Agriculture as the mainstay of the Government, the relevant division of cooperation and coordination. After the implementation of Law of Quality Safety of Agricultural Products, on the adjustment of division of supervision sectors of quality safety of agricultural products, the principles that agricultural sector is responsible for the supervision and administration of quality 
safety of agricultural products and segment of the food safety regulatory are not applicable to circulation of agricultural products. Generally, but rather by market or by designated agricultural products safety and quality supervision, the circulation of quality safety of agricultural products is not regulated by the business sector, a joint regulation by the departments in accordance with statutory functions. It makes safety supervision and management of agricultural products more reasonable and more standardized.

After the implementation of Law of Quality Safety of Agricultural Products, although it has compensated for the cold chain logistics and safety regulatory legal gaps in the law to a certain extent, but as a basic law, it is difficult to solve the many regulatory problems of imperfect legal system. The laws of agricultural products cold chain logistics safety supervision are not smooth. There is a positive or negative conflict between different departments in the laws and regulations.

In respect of standard system infrastructure of cold chain logistics of agricultural products, it is lack of product quality and safety system that adapts to the market economy development, and needs to be further improved.

The outline of paper is: Firstly, to do the current situation analysis of agricultural products cold chain logistics safety supervision system; then, to propose a number of system improvements; finally, to propose supervision measures.

The objective of paper is: through the discussion of safety supervision system at the present stage, putting forward improvement measures of safety supervision system and the corresponding supervision measures, to provide better ways and guarantee for building safety supervision system.

The innovation of this paper is to put forward to improve the supervision system from three aspects: government led, market guidance and association.

\section{Current Situation Analysis of Safety Supervision System of Cold Chain Logistics of Agricultural Products}

\subsection{Safety Supervision System of Cold Chain Logistics of Agricultural Products Improves Rapidly, but It Is Not Sound}

In 2004, the State Council issued the decision of the State Council on further strengthening food safety ((2004), 23rd) to state supervision system of quality safety of agricultural products clearly: according to the principles of a regulatory process overseen by a Department of, take the form of segmented supervision, varieties of supervision as a supplement, further straighten out regulatory functions of food safety [1].

Characteristics of quality safety management of cold chain logistics of agricultural products determines that it is a highly integrated system project, involving agriculture, health, environment, quality, Industry and Commerce, business, food and drug administration as other management and technical disciplines must be multisectoral and multidisciplinary co-operation. In real regulation, government departments do not straighten out the quality safety management system and clear the management and Division of functions, it is difficult to realize the agricultural products process management of "from farm to fork" of, pay attention to the management of agricultural product source, safety regulation linking to the circulation of agricultural products is not enough.

\subsection{Legal System of Safety Supervision of Cold Chain Logistics of Agricultural Products Perform Early Prototypes, but the System Is Not Complete}

Environmental regulation, agricultural inputs, production supervision and process control, market regulation, information releases, accident reports and related legal responsibilities and other supporting regulations of law of quality safety of agricultural products have not yet been effectively established. Meanwhile, poor coordination and operational, the existing punitive provisions of certain regulations is not enough. This affects not only the regulatory effect, makes administration according to law on farm produce quality and safety supervision is difficult to implement, it is difficult to achieve whole-process supervision system of "farm to fork" and appears unable to follow, random situations [2].

\subsection{Safety Standards of Cold Chain Logistics of Agricultural Products, Inspection and Certification and Accreditation System Needs to Be Improved}

According to statistics, the cold chain logistics criterion of different industries and sectors has reached nearly 200, but systematic, coordination of standards and operation and some aspects have many other problems. On 
September 11, 2009, the national standardization Management Commission official reply on that cold chain logistics standardization Committee was formally established on November 30, it marked that the standardization work of the national cold chain logistics is on the legalized track. In recent years, standardization system construction of the cold chain logistics has speed up, with rapid development in the industry promoting, industry associations, universities and enterprises actively participate in standards development work, a number of classification and basic requirements of cold chain logistics, cold storage management standards and other country standardization much-needed published.

Safety system of cold chain logistics of agricultural products is a tool that enhance the quality and safety supervision, maintain agricultural products important safety. In terms of products inspection and testing system, china planned and constructed 280 quality inspection center of agricultural products of State-level and ministerial level, and also directs the national one-third of the cities and counties to establish inspection stations of agricultural products quality and safety, instrument and equipment of agricultural inspection agencies and testing capacity have been further enhanced. However, agricultural products quality inspection center or laboratory is mainly managed by food safety supervision departments at all levels, it is on behalf of external supervision of Government, but internal detection capacity of circulation enterprises of food production had not been established [3]. At present, the number of inspection agencies in China also cannot meet the current needs, number of quality inspection institutes is insufficient, institutional instruments of agricultural products are backward and slow speed in some places that unable to meet the requirements of high volume and rapid detection.

Market access system is an important means to ensure the safety of cold chain logistics, China has yet to establish a sound market access system of cold chain logistics service of agricultural products. Market access system is linked with service market of cold chain logistics in China, and Chinese cold chain logistics services diversify our business tends to be smaller in size. Due to the low level of organization of the logistics market, cold chain logistics service system of agricultural products is difficult to establish.

Agricultural products in the circulation have not strict logistics service access system, inspection and quarantine system is not sound. agricultural products of market trade are neither package nor identity, it can not avoid contaminated agricultural products entering the market and into the hands of consumers in circulation, causing the occurrence of quality safety of agricultural products.

\subsection{Information Traceability System of Cold Chain Logistics of Agricultural Products Has Been Increased, but the System Is Still Not Sound}

The construction guidelines of speeding up meat and vegetable circulation traceability system during "TwelveFive" period issued by the Ministry of Commerce in October 2011 proposes that china will speed up meat and vegetable circulation traceability system during the "Twelve-Five" period and establish a sound meat vegetable circulation system at the end of "Twelve-Five" period. At present, Chinese agricultural products traceability system is in the fast-growing, some model cities has achieved good results in the full traceability model of agricultural products of meat and vegetable category, but there are some problems that we pay attention to the produce information traceability of agricultural products, and are lack of circulation information traceability of many links, it had a negative impact on the quality and safety of agricultural products. agricultural products as a special product, consumers even through observation, purchasing and consumption still unable to identify the quality of certain agricultural products, in order to reduce this distrust, enterprises and producers will pass quality information of agricultural products to consumers through the label, therefore, regulating agricultural products from production to the table of the whole safety information label is important to guarantee the quality and safety. But at present, most agricultural products have not labels, especially for agricultural products in bulk. Some agricultural products label is not standard, even false content. Producers and dealers did not use standard printing method to avoid responsibility.

\section{Mechanism Improvement of Safety Supervision System of Cold Chain Logistics of Agricultural Products}

Through the analysis of safety supervision system of cold chain logistics of agricultural products, sound supervision mechanism is the prerequisite that mobilize the body's enthusiasm and improve our preconditions for cold chain logistics of agricultural products quality safety supervision level. Currently China agricultural cold chain logistics quality security regulatory exists with source regulatory poor, and regulatory sector duties Divi- 
sion unknown, and market owners and consumers' security consciousness not strong and so on, due up the most fundamental reason is that regulatory mechanism is not sound [4]. Exploring mechanism improvement of safety supervision system of cold chain logistics of agricultural products can be as follows.

\subsection{Governments Leading: Clarifying the Government's Supervision Division Mechanism}

In quality safety supervision of cold chain logistics of agricultural products, the Government plays the leading role, mainly because the Government has the organizational advantage, has a force of monopoly, governments can use government authority to announce the quality and safety information and it is credible. In recent years, countries have promulgated the laws and regulations of law of quality safety of agricultural products, law of food safety and so on, quality safety of agricultural products comes into the new stage of regulation [5]. Law of quality safety of agricultural products, law of food safety and other laws rule the Government supervisory duties, also give the Government regulatory powers. However, due to legal legislation and the supervision system in our country is not sound, government departments do not straighten out the quality safety management system and clear the management and Division of functions, it is difficult to realize process management of the agricultural products "from farm to fork", it makes supply chain supervision of agricultural products have the coexistence of crossing and vacancies. To give full play of Government's cold chain logistics of agricultural products quality safety supervision must sort out the mechanism for the Division of the various government departments, including several aspects: firstly, to clear quality safety supervision departments of cold chain logistics of agricultural products. quality safety supervision of Circulation of agricultural products in China involving agriculture, quality inspection, business, health, food and drug supervision and management, business, and more than 10 departments, but do not clear the logistics services safety regulation in the circulation of agricultural products, management of many circulation departments inevitably result in departmental duties overlapping or gaps in regulation, lack of circulation supervision makes safety management process of agricultural products” From farm to table" achieve difficultly. Establishing quality safety supervision departments of cold chain logistics of agricultural products, sorting out division mechanism of supervisory duties of the relevant functional areas is the important support to build an efficient regulatory system. Secondly, to clear regulatory Division of the agricultural products supply chain. safety supervision of agricultural products supply chain "from farm to fork" during the whole process involves a number of administrative departments, departments should establish mechanisms for coordination and cooperation, and do all aspects of regulatory compliance, all aspects of departmental management, all aspects of sectoral responsibilities throughout the effective monitoring mechanism. Thirdly, to establish a mechanism by departments of the central and local governments. According to the provisions of the law, local governments bear overall responsibility for quality safety of agricultural products, so supervision departments of the Central implement quality safety supervision of agricultural products, need strong support from local Governments, guide local departments of all levels to carry out territorial responsibility, improve the teams and institutions of quality safety, ensure the smooth implementation of quality safety supervision of agricultural products.

\subsection{Market Guiding: Strengthening Guidance Mechanism of Market Supervision}

To maximize the benefits is the core of objectives of the enterprise in the market, only quality safety supervision of the cold chain logistics of agricultural products can bring tangible benefits to the enterprise, market players have enthusiasm to input human, material and financial resources for supervision over safety. Under safety supervision system of government-led, market regulation of cold chain logistics quality and safety of agricultural products is only focused on accountability, good market incentives and guidance mechanism has not been established. Strengthening quality safety supervision of cold chain logistics of agricultural products should play the role of enterprises in the market, cultivate Market main body of awareness of self-discipline, making them have awareness of active supervision and administration of the market order. Regulatory guidance mechanism of the market approaches can start with the following: firstly, to play the leading enterprises' leading and exemplary role. Just to get through government policies or subsidies to enterprises, guiding the enterprises to form the self-regulatory mechanism of the safety supervision, through independent regulatory to form a good corporate reputation, and ultimately through market price to form compensation of mechanism market to supervision costs. Secondly, to strengthen supervision cold chain logistics aspects of agricultural products. Cold chain logistics of agricultural products are links ties between production and consumption, it is the key to enhance the quality and 
safety supervision. So, to make checks on market access of cold chain logistics of agricultural products, in agricultural circulation link especially sales link, we must establish up a specification, and sound management system, and make market access of Cold chain logistics of agricultural products comply with rules and laws, to improve quality safety supervision system of cold chain logistics of agricultural products. To qualify for the institutional protection services provide seamless cold chain logistics of agricultural products into the market, while can will not qualified agricultural cold chain logistics service refused of "market" outside, to increased initiative of enterprises participating regulatory system. Thirdly, to optimize the distribution of interests and coordination. Mechanisms and systems make cold chain logistics enterprises of agricultural products reap sustainable benefits, it is the main approach for the cold chain logistics service companies to enhance quality and safety awareness, Chinese logistics industry rapidly develops, lack of market access system and market order is not standard, it makes standardized enterprises interests of cold chain logistics of agricultural products had not been well maintained, the enthusiasm of enterprises had been frustration. Therefore, must optimizing the profit allocation mechanism and benefit coordination mechanism to mobilize the enthusiasm of enterprises of the cold chain logistics of agricultural products.

\subsection{The Association Promoting: Establish Restraint Mechanism of Self-Discipline}

In the safety supervision mechanism of cold chain logistics of agricultural products quality should sufficiently pay attention to the role of industry associations, establish effective mechanism of Profit-driven, Inspire the enthusiasm of industry associations in the quality safety supervision of the cold chain logistics of agricultural products.

Industry associations should have consciousness of active supervision and management of the market order. Establishing restraint mechanism of self-discipline is an important aspect to establish profit-driven mechanism of social middle-tier building industry association. an important starting point of establishing industry associations is to strengthen the industry's self-regulation. No self-regulatory mechanisms, trade order is chaos, it will reduce the efficiency of the sector, damaging the interests of consumers. Associations are indeed the complex of interests of industry, any industry member must abide by its rules, or the other members will be excluded from the industry. self-regulatory mechanisms of Industry associations plays an important role in the quality safety regulation of agricultural products, but because of the Government's external intervention and System defects of the association itself, the associations did not form independent and democratic mechanism. Maintaining industry overall interests is target and purposes for industry associations to pursuit, so, we should establish series of profit-driven mechanism to inspire self-discipline enthusiasm of Industry Association, guide industry association to comply with specification market order, established sound managed and constraint mechanism of industry self-discipline, improve the self-regulating management system, Develop and implement the code of professional ethics of associations, regulating member behavior to coordinate members' relationships, Earnestly shoulder important responsibilities of industry self-regulation and guarantee the social responsibility of quality and safety.

\section{Supervision Measures of Cold Chain Logistics of Agricultural Products}

At this stage, quality of agricultural products in China is not satisfied, of which agricultural products' quality and security incidents caused by the cold chain logistics service often occur. In recent years, the "rancid" event happened in a dairy in Shanghai because of imperfect cold chain, a well-known food companies "naked games", and "fresh meat" event which is very sensitive to temperature, and these cold-chain logistics security news events often can be found in newspapers. CCTV financial channel planned and designed "the break cold chain" program makes in-depth feature stories about number problems on the cold chain of domestic market in 2012. It is also a alarm to the cold chain logistics secure service and make the vast majority of consumers and Governments focus on cold chain logistics services' security.

Commodity circulation quality control has become the focus of social increasing concern [6]. From the perspective of international agricultural circulation industry development experience, developed countries have set up the "from field to table" integrated cold chain logistics systems, not only to ensure the products' quality, but also to improve agricultural efficiency. After 30 years' development of reform and opening up, the adjustment of agricultural structure in China achieved remarkable results and regional and varieties are increasingly optimized layout, so circulation of agricultural products has shown the characteristics of large scale, long distance, off-season. This puts forward higher requirements to cold-chain logistics for agricultural products' services and 
efficiency. Cold chain logistics involves services' demanders of agricultural products, regulators and consumers, and other interests of the parties. Their effectiveness depends not only on the parties' own choice, but also depends on the other two aspects of the policy, and there are a series of games between them. From the perspective of game and balance, Henson who from United Kingdom and Professor Caswell from United States think regulation is a game between the different stakeholders, the choice of security policies is the result of the game between interest groups [7].

This study is based on cold chain logistics characteristics of agricultural products, points out that the Government as guardian of the public interest, and it has an obligation to regulate enterprises that providing cold chain logistics services. Addressing regulatory failures of market mechanisms also need to appeal to the public goods of Government, who offers a wide range of regulatory measures. This part of the study focused on the dynamic game between government regulators and providers of cold chain logistics services of agricultural products, and the interaction between both of them is direct basis to improve the regulatory rules, regulatory procedures and supervision measures.

The supervision quality and safety of cold chain logistics of agricultural products is a complex, long-term projects. We should focus on improving legal system, inspection systems, quality certification system, incentive mechanism and information sharing mechanism of agricultural products quality and safety supervision system and building "linkage" of " $3+2$ " of the stereo monitor system.

\subsection{Set up Complete Supervision System of Quality and Safety of Cold Chain Logistics of Agricultural Products}

Cold chain logistics of agricultural products is the key to circulation and safety of agricultural products, and it is related to urban consumers' security of lives and property, so supervision quality and safety of cold chain logistics of agricultural products mainly relies on the Government to enact laws to peremptory norms and market's discipline to improve the regulatory system. According to the agricultural products of its own property and produce irreversible characteristics throughout the cold chain logistics of agricultural products, we know we should establish an integrated of law regulations and standards of cold chain logistics supervision system to match international standards and integrate Central and local governments, forming the law regulations and standards across the supply chain departments with the coordination. By the sound legal system of Central and local authorities at vertical levels to establish an effective system of law enforcement, and through the legal system for the vertical covering quality and safety forecasting, safety warnings, process of quality and safety and evaluation of quality and safety, to implement effective regulatory control of problems before, during and after they happen.

\subsection{Improve the Inspection and Testing of Quality and Safety System of Cold Chain Logistics of Agricultural Products}

We should gradually improve test detection system, increase input funding of detection equipment, strengthen detection personnel training, and constantly improve business quality and detection level of staff whose working is related to agricultural cold chain logistics quality and safety in our country. This can make detection institutions can test the condition of quality and security in agricultural cold chain logistics service's process effectively, and timely announce detection information to consumers and regulatory institutions, which ease asymmetric information between enterprises who providing service and consumers and regulatory sectors.

To establish routine regulation of agricultural products' quality, gradually expanding breadth and depth of routine regulation of agricultural products' quality. On this basis, establish rating credit records of agricultural cold chain logistics service and encourage enterprises who providing service attach importance to service quality and safety.

\subsection{Improve Certification System of Quality of Cold Chain Logistics of Agricultural Products}

Safety certification of quality of cold chain logistics of agricultural products means cold chain logistics safety supervision and management departments' effective control means and methods. Certification system, which will benefit the consumers obtain reliable information, can also play a role in guiding enterprises who providing service, to prevent the "market for lemons" problems, and ensure high quality and price advantages, enhance the 
enthusiasm of enterprises to pay attention to the quality of service.

\subsection{Improve Rewards and Punishments of Regulatory Mechanism}

At present, the weak regulatory enforcement is one of the major reasons why enterprises do not pay attention to the quality of service, then strengthen supervision from the "prizes" and "corrections" in two ways. Firstly, States should incentive regulatory sectors which seriously perform their duties. When regulators complete a task very well and guarantee the quality of the cold chain logistics, the Country should give them the right kind of incentives to raise enthusiasm among government departments and meanwhile reduce regulatory abuse due to departmental interests [8]. Secondly, superior competent sector should increased punishment to dereliction of behavior of regulatory sector and establish evaluation system of effective performance. Establishing sound assessment and responsibility held system of regulatory sector can introduce general people's enthusiasm and social supervision, which can reduce dereliction of behavior, and force regulatory sector supervise enterprises who providing service, maintenance fundamental interests of social and general people. Cold chain logistics quality and safety supervision in our country lacks of an effective accountability system. In china, the phenomenon of lax enforcement and impunity occur because there is no responsibility system related to dereliction of behavior. Government is failed to act like this, so it is necessary to strengthen the supervision of government regulators, strengthen accountability to press it to fulfill his supervisory duties. Increase the rewards and penalties to regulators, prompt law enforcement officers fulfill their duties, and prevent the occurrence of corruption and malfeasance [9].

\subsection{Innovate the Mechanism of Information Sharing between Regulators}

The expectation of the degree of difficulty that cold chain logistics companies supervise their regulatory sectors is one important reason why they ignore service quality and security. Then reduce the difficulty of supervision by regulators can be multi-pronged. Firstly, implement indentified information system of the cold chain logistics' safety and visualize the secure information. Labels look like "identification" of cold chain logistics of agricultural products and accurately passed on to consumers about basic information, services and other information of enterprises, which helps improve service enterprises' brand, and also reduces the cost of regulators to search for security information. Secondly, establish a cold chain logistics traceable system of agricultural products. Building cold chain logistics quality and safety traceable system for agricultural products is a part of the overall management to protect the quality of the cold chain logistics and safety from "farm to table" necessary. When the quality and safety incident occurs, Government can find products and responsible persons based on labels, logos, marketing databases, transaction voucher and so on to take effective measures to prevent the incident from spreading, and hold accountability. Thirdly, strengthen coordination among regulators. Quality supervision and coordination is the key to successful cooperation in logistics service supply chain. The "regulatory" problems in the process of products' quality supervision and their consequences have become an important factor in block the effectiveness. It is imperative to straighten out the regulatory functions. All departments related to cold chain logistics' services should perform their respective duties, reduce cross-management and multi-management caused by unclear responsibilities, so that each link has a specific department directly. Fourth, enlarge the application of advanced control technology. With the development of information technology, regulators can use full temperature control, in transit tracking, Internet and other advanced technology to connect supervision departments and enterprises effectively, real-time monitoring, lower the cost of government's regulation, and increase the efficiency of governments' regulation.

\section{Conclusion}

Through the improvement and measures analysis of agricultural products cold chain logistics safety supervision system, it makes cold chain logistics of agricultural products quality safety in China more efficient, and makes management implementation have laws to follow and have meters can do.

\section{Acknowledgements}

The fund project, the National Social Science Fund "The research of fresh agricultural products cold chain logistics management system for the needs of the city” (11BJY111). 


\section{References}

[1] Chen, Z.Y. (2013) Discussion on Quality Safety of Agricultural Products Division of Regulatory Responsibilities. Food Industry at Home and Abroad (Second Half), 5, 40-41.

[2] Wang, P.X. and Wang, X.L. (2012) Improve Agricultural Product Quality and Safety Control System. Anhui Agricultural Sciences, 40, 2477-2478.

[3] Liu, X.J., et al. (2012) Third Party Testing Traceability and Certification of Agricultural Products Quality Outsourcing Service Mode. Guangdong Agriculture Science, 39, 192-195.

[4] Li, C.J., Yang, C. and Liang, J. (2009) Analysis on the Dynamic Mechanism of Agricultural Products Quality Safety Supervision. Journal of Guangxi University of Finance and Economics, 22.

[5] Jin, F.Z. (2011) Reflection on Construction of Supporting System of Agricultural Products Quality Safety Supervision and Business. The Quality and Safety of Agricultural Products, 6, 8-10.

[6] Yang, Y.F. (2010) Discussion on the supervision of commodity quality in circulation field from the perspective of information asymmetry. Productivity Research, 7, 142-150.

[7] Henson, S. and Caswell, J. (1999) Food Safety Regulation: On Overview of Contemporary Issues. Food Policy, 24, 589-603. http://dx.doi.org/10.1016/S0306-9192(99)00072-X

[8] Li, Z.T. and He, Z.W. (2012) Food Quality and Safety Supervision Based on Evolutionary Game Theory Analysis of China. Chinese Agricultural Science Bulletin, 28, 313-316.

[9] Chen, X.J. and Feng, X.Y. (2012) Study on Food Safety Based on the Game. Journal of Anhui University of Technology (Social Science Edition), 29, 24-26. 